\title{
Prevalence, 20-month incidence and outcome of unipolar depressive disorders in a community sample of adolescents
}

\author{
A. J. OLDEHINKEL, ${ }^{1}$ H.-U. WITTCHEN AND P. SCHUSTER \\ From the Max Planck Institute of Psychiatry, Clinical Psychology and Epidemiology Unit, Munich, \\ Germany; and Department of Psychiatry, University of Groningen, The Netherlands
}

\begin{abstract}
Background. This article presents prospective longitudinal findings on prevalence, incidence, patterns of change and stability of depressive disorders in a community sample of 1228 adolescents.

Methods. Data were collected at baseline and follow-up (20 months later) in a representative population sample of 1228 adolescents, aged 14-17 at baseline. Diagnostic assessment was based on the Munich Composite International Diagnostic Interview (M-CIDI).

Results. The overall cumulative lifetime incidence of any depressive condition was $20.0 \%$ (major depressive disorder (MDD), 12.2\% ; dysthymia, 3.5\%; subthreshold MDD, $6.3 \%$ ), of which about one-third were incident depressions in the period between baseline and follow-up. Depressive disorders rarely started before the age of 13 . Females were about twice as likely as males to develop a depressive disorder. Overall, the 20-month outcome of baseline depression was unfavourable. Dysthymia had the poorest outcome of all, with a complete remission rate of only $33 \%$ versus $43 \%$ for MDD and 54\% for subthreshold MDD. Dysthymia also had the highest number of depressive episodes, and most psychosocial impairment and suicidal behavioural during follow-up. Treatment rates were low (8-23\%). Subthreshold MDD associated with considerable impairment had an almost identical course and outcome as threshold MDD.
\end{abstract}

Conclusions. DSM-IV MDD and dysthymia are rare before the age of 13, but frequent during adolescence, with an estimated lifetime cumulative incidence of $14 \%$. Only a minority of these disorders in adolescence is treated, and more than half of them persist or remit only partly.

\section{INTRODUCTION}

Over the past decade, various community studies reported that depression is a frequently occurring mental disorder among adolescents. However, estimated prevalence rates for DSM major depressive disorder (MDD) in this age group (roughly defined as 14-19 years) show considerable variation. Lifetime prevalences range from $4 \%$ (Whittaker et al. 1990) to $24 \%$ (Lewinsohn et al. 1993), 1-year prevalences from $4 \%$ (Fergusson et al. 1993) to $17 \%$ (Feehan et al. 1994) and point prevalences from $3 \%$

1 Address for correspondence: Dr A. J. Oldehinkel, Max Planck Institute of Psychiatry, Clinical Psychology and Epidemiology Unit, Kraepelinstrasse 2, 80804 München, Germany.
(Lewinsohn et al. 1993; Feehan et al. 1994) to $6 \%$ (Blazer et al. 1994). This variation is assumed to be mainly due to differences in assessment instruments and diagnostic criteria of depressive disorders, sampling and design, and to the time the respective study was conducted (Kovacs \& Gatsonis, 1994). The recent American Academy of Child and Adolescent Psychiatry consensus (AACAP, 1998) estimated the prevalence of MDD in adolescents to be $4-8 \%$, and the cumulative incidence by the age of 18 to be approximately $20 \%$, based on the study by Lewinsohn et al. (1993).

Rates of depressive disorders in childhood (defined as below the age of 14) were found to be considerably lower. Findings suggest that it is 
only after the age of 13 that cumulative incidences rise sharply, with peak incidences between ages 15 and 18 (Fleming et al. 1989; Burke et al. 1990; Fleming \& Offord, 1990; Lewinsohn et al. 1992; Kessler et al. 1993; Hankin et al. 1998; Steinhausen et al. 1998). However, when evaluating prevalence rates and age-of-onset characteristics of depressive disorders in the transition period from childhood to adolescence, we need to acknowledge some potential assessment problems. In the first place, standardized diagnostic interviews for adults, such as the Composite International Diagnostic Interview (CIDI, WHO, 1990), the Diagnostic Interview Schedule (DIS, Robins et al. 1981) and the Schedule for Affective Disorders and Schizophrenia (SADS, Orvaschel et al. 1982) appear to work well in persons over 14 years of age, but it is generally agreed that younger children may need different assessment strategies, such as the Diagnostic Interview Schedule for Children (DISC, NIMH, 1992) and the Child and Adolescent Psychiatric Assessment (CAPA, Angold et al. 1995). Parents or teachers are normally used as (additional) sources of information. Furthermore, clinically valid diagnoses of depression in children may require slightly different diagnostic criteria. Although Kovacs (1996) reported similar features of MDD across juvenile and older patients in clinically referred samples, the symptom presentation and duration of depression may differ between children and older persons in community samples. The recent DSM-IV criteria for childhood MDD and dysthymia are consistent with this in that mood may be irritable instead of depressed, and that the duration of dysthymia should be at least one year instead of two.

One could assume that the relative rarity of childhood depression and prepubertal onsets in most studies is an artefact of the strict criteria of DSM, which may be appropriate in adults, but not in children, and hence expect to find considerably higher proportions of various forms of MDD just falling short of diagnostic criteria (defined as subthreshold MDD) in children and (young) adolescents. In a study among 9-13-year-olds, Costello et al. (1996a) found that strictly diagnosed DSM-III-R diagnoses were rare, but that there was a substantial group of children who had the core symptoms of mood disorder and anhedonia but did not reach the criterion either for duration of dysthymia, or for the number of symptoms of MDD. Similarly, Cooper \& Goodyer (1993) noted that a large proportion of their sample of 11-16-year-old girls reported depressive symptoms but did not meet DSM-III-R criteria for MDD. Correspondingly, some authors stress the importance of assessing subsyndromal forms of depression and hence favour the use of more lenient diagnostic criteria (Lewinsohn et al. 1994; AACAP, 1998). On the other hand, others believe that the DSM-III(-R) criteria for MDD may not be strict enough, as many adolescents with DSM-III(-R) MDD seem to be functioning adequately (Jensen et al. 1993; Verhulst et al. 1997). Therefore, Roberts et al. (1998) and Costello et al. (1996b) recommend strongly the use of both symptom and impairment criteria when determining caseness. These ongoing discussions clearly signal the need for a broader assessment of depressive disorders beyond strictly defined DSM-IV criteria for MDD, by using varying symptom and impairment criteria. Exploration of subthreshold conditions might offer guidance about more suitable diagnostic threshold criteria for depression in (early) adolescence.

Consistent with findings in adult depression, epidemiological studies in adolescents revealed that females are affected about twice as frequently as males. Many studies reported approximately the same rates for boys and girls in children, and an increase in gender differences in middle-to-late adolescence (Kashani et al. 1989; Burke et al. 1990; Petersen et al. 1993; Ge et al. 1994; Birmaher et al. 1996; Angold et al. 1998; Hankin et al. 1998), although others failed to find a significant age by gender interaction (Lewinsohn et al. 1993; Simonoff et al. 1997).

These findings, as well as the many major social and biological changes taking place in adolescence, indicate that this period might be crucial for our understanding of onset mechanisms of depressive disorders (Hankin et al. 1998). The ideal way to identify onset mechanisms and aetiological and pathogenetic implications are longitudinal studies in general population samples, providing information about the forms, severity, stability and incidence, as well as about the outcome of depressive disorders in 
adolescence. Studies meeting those criteria are still relatively rare (Roberts et al. 1998). More knowledge about the nature of depression in adolescents is also essential for various other reasons: (a) adolescence is a period in which subjects make important developmental choices, which may be seriously affected by depressive symptoms; (b) depressive symptoms can lead to unfavourable consequences such as substance abuse and impairment in interpersonal relationships and global functioning (e.g. Birmaher et al. 1996); (c) early onset of depressive disorder strongly increases the risk for recurrent depressive disorders during adulthood (Harrington et al. 1990; Rao et al. 1995; Kovacs 1996; Pine et al. 1998). A better understanding of the magnitude and form of adolescent depression, its natural course and outcome may contribute to setting more appropriate priorities for prevention and treatment.

\section{Aims}

This paper reports findings from the Early Developmental Stages of Psychopathology (EDSP) Study, a large longitudinal populationbased survey of adolescents and young adults (aged 14 and over) in Munich, Germany, which focuses on three main areas, as follows.

1 The baseline and follow-up prevalence as well as the 20-month incidence of mild, moderate and severe forms of MDD, dysthymia, and subthreshold MDD, which is defined as falling short of one of the DSM-IV criteria for MDD.

2 Similarities and differences between threshold and subthreshold MDD regarding age-of-onset characteristics, course, and impairment. We hypothesize that subthreshold MDD is more likely to have an early (childhood) age of onset and is more prevalent in early adolescence than threshold MDD.

3 The symptom and diagnostic stability of adolescent depressive disorder over the followup period of 20 months, by examination of the natural course and various symptom and psychosocial outcome measures at follow-up.

Furthermore, we will examine similarities and differences between two forms of subthreshold MDD, namely subthreshold MDD falling short of the required number of symptoms and subthreshold MDD lacking the impairment criterion.

\section{METHOD}

\section{Sample}

The data presented here were collected as part of the Early Development Stages of Psychopathology (EDSP) study, a research programme funded by the German Ministry of Research and Technology, whose mission is to study the prevalence, incidence, risk factors, natural course and interrelationships of a wide range of mental disorders and substance abuse in adolescents and young adults in a prospective way. A detailed description of the methods used in the EDSP study has been reported elsewhere (Wittchen et al. 1998a,b). Very briefly, the EDSP study involves a baseline (completed in 1995) and two follow-up surveys, the first of which was completed in 1997 . The sample was drawn from the 1994 government registers of residents in metropolitan Munich including the more rural surrounding counties, from all registrants expected to be 14-24 years old during the first half of 1995. Because of the low birth rate in the youngest age cohort and the aim of

Table 1. Distribution of sociodemographic variables at baseline (weighted estimates)

\begin{tabular}{|c|c|}
\hline & $\%$ \\
\hline \multicolumn{2}{|c|}{ Current educational status or employment } \\
\hline Hauptschule & 8.9 \\
\hline Realschule & $19 \cdot 9$ \\
\hline Fachhochschule & $4 \cdot 1$ \\
\hline Gymnasium & $57 \cdot 0$ \\
\hline University & $8 \cdot 4$ \\
\hline Unemployed & $0 \cdot 9$ \\
\hline Employed & $0 \cdot 8$ \\
\hline \multicolumn{2}{|l|}{ Living arrangement } \\
\hline With both parents & $74 \cdot 8$ \\
\hline With single parent & $24 \cdot 5$ \\
\hline Alone & $0 \cdot 7$ \\
\hline \multicolumn{2}{|l|}{ Social class } \\
\hline I lowest & $0 \cdot 1$ \\
\hline II lower middle & $4 \cdot 4$ \\
\hline III middle & $62 \cdot 2$ \\
\hline IV upper middle & $29 \cdot 1$ \\
\hline V upper & $4 \cdot 2$ \\
\hline \multicolumn{2}{|c|}{ Subjective financial situation } \\
\hline Very bad & $0 \cdot 0$ \\
\hline $\mathrm{Bad}$ & 3.6 \\
\hline Not good, not bad & $25 \cdot 9$ \\
\hline Good & $57 \cdot 2$ \\
\hline Very good & $13 \cdot 3$ \\
\hline \multicolumn{2}{|l|}{ Urbanicity } \\
\hline Suburbs & $27 \cdot 6$ \\
\hline Central Munich & $72 \cdot 4$ \\
\hline
\end{tabular}


having a sufficiently high number of cases unaffected by mental disorders and psychotropic substance abuse, persons aged 14-15 were sampled at twice the probability of those aged 16-21, and 22-24-year-olds were sampled at half this probability. The present analysis on adolescent depression is restricted to respondents aged $14-17$ at baseline $(N=1395)$.

The baseline response rate among 14-17-yearolds was $74.3 \%$, and the first follow-up was completed in 1228 cases (response rate $88.0 \%$ ). Although originally the follow-up investigation was planned after a 12-month interval, this turned out to be technically unfeasible because of the sample size. Thus, the actual median time interval between baseline and follow-up was $19 \cdot 7$ months, with a range of 14 to 24 months. All data presented in this paper originate from the respondents themselves, for whom both individual and parents' informed consent was obtained. To account for the above-mentioned differential sampling probabilities, individuals who could not be located and refusal to participate, the data have been adjusted by age, gender and geographic location to match the distribution to the original sampling frame. For a more detailed description see Wittchen et al. $(1998 a, b)$.

Table 1 shows the distribution of sociodemographic variables at baseline. Almost all subjects were attending school $(90 \%)$ or university $(8 \%)$ and were living with their parents $(99 \%)$ at the time of the first interview. The most frequent school type was the Gymnasium (similar to high school), followed by the Realschule (an intermediate type of schooling) and the Hauptschule (providing the mandatory 10year basic schooling). Only very few respondents in this group were employed or unemployed. The majority of the respondents were classified as middle class $(62 \%)$, reflecting the population of Munich. Noteworthy changes in sociodemographic characteristics from baseline to follow-up were only found for school and employment status, with $21 \%$ of the respondents having changed to job training programmes.

\section{Diagnostic assessment}

Face-to-face computer-assisted interviews were administered by professional health interviewers and clinical psychologists at baseline and by clinically trained interviewers only at follow-up.
Both at baseline and follow-up, diagnostic assessment was based on the Munich version of the Composite International Diagnostic Interview (M-CIDI; Wittchen \& Pfister, 1997). At baseline the lifetime version of the M-CIDI was used to compute DSM-IV (APA, 1994) diagnoses over a period of the past 12 months and lifetime (lifetime covering the past 12 months and the period before). In the follow-up investigation, the follow-up version of the M-CIDI (Wittchen \& Pfister, 1997) was used to evaluate symptoms and diagnoses during the previous 12 months and the whole follow-up interval. The M-CIDI is an updated version of the World Health Organization's CIDI version 1.2 (WHO, 1990), which incorporates questions to cover DSM-IV and ICD-10 criteria. The M-CIDI allows for the assessment of symptoms, syndromes and diagnoses of 48 mental disorders, supplemented with information about onset, duration, clinical and psychosocial severity, and health service utilization. Reliability and procedural validity findings for the M-CIDI have been reported elsewhere (Lachner et al. 1998; Reed et al. 1998; Wittchen et al. 1998 c), along with detailed descriptions of its format and structure. Briefly, findings for depressive disorders in a sample of 60 subjects aged 14-24 revealed a test-retest reliability (kappa) of 0.68 for MDD and 0.70 for dysthymia. Test-retest reliability for age of onset of depressive disorders was high for depressive episode (intraclass coefficient $=0.97$ ) and moderate for dysthymia (intraclass coefficient $=0 \cdot 60$ ). Clinical validity as compared to best estimates clinical information was found to be excellent (kappa $=0.95$, base rate $26 \%$ ) for MDD and moderate (kappa $=0.54$, base rate $10 \%$ ) for dysthymia. The MCIDI DSM-IV algorithms allow for further subtyping of single and recurrent episodes of MDD by severity (mild, moderate, severe) according to DSM-IV's respective specific. Furthermore, it is possible to compute a diagnosis of subthreshold MDD, using the WHO-CIDI algorithm (Üstün \& Sartorius, 1995). This diagnosis is assigned when respondents fall short of just one diagnostic criterion, by failing to report either the mandatory five of a total of nine symptoms (criterion A). Or clinically significant distress or impairment (criterion C). In addition, we defined the category 'symptomatic depression' as the presence of at least two 
depression symptoms for at least 2 weeks, but neither MDD nor dysthymia nor subthreshold MDD. Unless otherwise stated, diagnostic findings reported in this paper are based on the M-CIDI DSM-IV algorithms without using the exclusion criteria for dysthymia. According to DSM-IV rules, the diagnosis of dysthymia can only be made if the dysthymic disorder was established at least 2 years prior to the first major depressive episode (if any), or if there has been a full remission of at least 2 months of the major depressive episode before the onset of dysthymia (APA, 1994). About $40 \%$ of the respondents with dysthymia also had a lifetime diagnosis of MDD and $16 \%$ met the DSM-IV exclusion criteria. Other DSM-IV diagnostic exclusions, however, were taken into account. Thus, depressive syndromes fully accounted for by bereavement, bipolar disorder, substance disorder or general medical conditions were not counted as depressive disorders throughout the paper.

\section{Measures}

The following measures are used in this paper. 'Baseline prevalence' denotes the weighted rates of occurrence of depressive disorders among respondents aged 14-17 at baseline, reported separately for disorders present during the 12 months preceding the interview and for disorders present at least once during lifetime. 'Incidence' is defined as the proportion of the sample with a new (incident) depression between baseline and follow-up. 'Twelve-month prevalence' rates at follow-up refer to DSM-IV criteria which were met within the 12 months preceding the followup interview. Finally, 'cumulative lifetime prevalence', or more accurately cumulative lifetime incidence, is - in principle - calculated by adding the diagnostic outcomes at baseline (lifetime prevalence) and the incidence in the follow-up period. However, since subthreshold MDD and MDD were classified hierarchically, respondents with a baseline diagnosis of MDD could not be incident subthreshold cases, but a baseline subthreshold MDD did not exclude the incidence of MDD between baseline and follow-up. In other words, some of the baseline subthreshold MDD cases turned into follow-up MDD cases. Furthermore, a baseline case of mild depression could turn into a follow-up case of moderate or severe depression, and a baseline moderate case could turn into a follow-up severe case, but the opposite was not possible. Because of these hierarchies, the cumulative lifetime incidence not may be the sum of the lifetime prevalence at baseline plus the incidence for subthreshold, mild, moderate and severe MDD.

\section{Statistical analysis}

Unless indicated otherwise, data were weighted to adjust for differential sampling probabilities, non-contact and non-response. To account for design effects introdued by the use of weighted data, statistical tests on weighted data were performed using the so-called svy (survey) commands of the statistical program STATA (StataCorp., 1997). A $P$ value $<0.05$ was considered statistically significant. Age-ofonset curves (cumulative hazards) were calculated by means of Kaplan-Meier estimates (Kaplan \& Meier, 1958).

\section{RESULTS \\ Selective drop-out}

Of all respondents aged 14-17 at baseline $(N=$ 1395), the participation at follow-up was $88 \%$ $(N=1228)$. The group who declined participation at follow-up did not differ from the group who participated with respect to baseline MDD $\left(x_{1}^{2}=0.004, P=0.95\right)$ and subthreshold $\operatorname{MDD}\left(\chi_{1}^{2}=0 \cdot 3, P=0.57\right)$, but contained significantly more persons with dysthymia $(7 \cdot 0 \%$ versus $\left.1.7 \%, \chi_{1}^{2}=12.9, P<0.01\right)$. Furthermore, the groups did not differ with regard to the proportion with any DSM-IV anxiety disorder $\left(\chi_{1}^{2}=0.8, \quad P=0.37\right) ; \quad$ or $\quad$ with obsessivecompulsive disorder, post-traumatic stress disorder, somatization disorder, or eating disorder $\left(\chi_{1}^{2}=1 \cdot 1, P=0 \cdot 30\right)$.

\section{Prevalence and incidence}

At baseline $13 \cdot 0 \%$ of the sample (14-17 years old) reported having had at least one of the depressive conditions listed (Table 2). Dysthymia was found to be quite rare $(1.7 \%)$; the majority fulfilled criteria for either MDD $(6.7 \%)$, mostly of moderate or severe type, or subthreshold MDD (5.3\%). About half of the baseline lifetime MDDs, two-thirds of the subthreshold MDDs and almost all dysthymic disorders were also 'active' during the 12 months preceding the interview, resulting in a 12-month 
Table 2. Weighted prevalence estimates with standard errors (S.E.) of M-CIDI DSM-IV depressive conditions at baseline and follow-up, 20-month incidence and cumulative incidence among respondents aged 14-17 years at baseline

\begin{tabular}{|c|c|c|c|c|c|c|c|c|c|c|}
\hline & \multicolumn{4}{|c|}{ Baseline } & \multirow{2}{*}{\multicolumn{2}{|c|}{$\begin{array}{l}\text { 20-month } \\
\text { Incidence }\end{array}$}} & \multicolumn{4}{|c|}{ Follow-up } \\
\hline & \multicolumn{2}{|c|}{ LT } & \multicolumn{2}{|c|}{ 12-month } & & & \multicolumn{2}{|c|}{ 12-month } & \multicolumn{2}{|c|}{ Cumulative LT } \\
\hline & $\%$ & (S.E.) & $\%$ & (S.E.) & $\%$ & (S.E.) & $\%$ & (S.E.) & $\%$ & (S.E.) \\
\hline \multicolumn{11}{|l|}{ Total group $(N=1228)$} \\
\hline Subthreshold MDD & $5 \cdot 3$ & $(0 \cdot 7)$ & $3 \cdot 5$ & $(0 \cdot 6)$ & $2 \cdot 1$ & $(0 \cdot 4)$ & $2 \cdot 9$ & $(0 \cdot 5)$ & $6 \cdot 3$ & $(0 \cdot 7)$ \\
\hline MDD & $6 \cdot 7$ & $(0 \cdot 8)$ & $3 \cdot 4$ & $(0 \cdot 6)$ & $5 \cdot 6$ & $(0 \cdot 7)$ & $6 \cdot 8$ & $(0 \cdot 8)$ & $12 \cdot 2$ & $(1 \cdot 0)$ \\
\hline Mild & $1 \cdot 1$ & $(0 \cdot 3)$ & $0 \cdot 7$ & $(0 \cdot 3)$ & $1 \cdot 8$ & $(0 \cdot 4)$ & $2 \cdot 4$ & $(0 \cdot 5)$ & $2 \cdot 8$ & $(0 \cdot 5)$ \\
\hline Moderate & $2 \cdot 4$ & $(0 \cdot 5)$ & $1 \cdot 1$ & $(0 \cdot 3)$ & $2 \cdot 0$ & $(0 \cdot 4)$ & $2 \cdot 3$ & $(0 \cdot 5)$ & $4 \cdot 2$ & $(0 \cdot 6)$ \\
\hline Severe & $3 \cdot 2$ & $(0 \cdot 6)$ & $1 \cdot 7$ & $(0 \cdot 4)$ & $1 \cdot 7$ & $(0 \cdot 4)$ & $2 \cdot 1$ & $(0 \cdot 5)$ & $5 \cdot 2$ & $(0 \cdot 7)$ \\
\hline Dysthymia & $1 \cdot 7$ & $(0 \cdot 4)$ & $1 \cdot 6$ & $(0 \cdot 3)$ & $1 \cdot 8$ & $(0 \cdot 4)$ & $2 \cdot 1$ & $(0 \cdot 5)$ & $3 \cdot 5$ & $(0 \cdot 6)$ \\
\hline Any (including subthreshold) & $13 \cdot 0$ & $(1 \cdot 1)$ & $8 \cdot 0$ & $(0 \cdot 8)$ & $7 \cdot 1$ & $(0 \cdot 8)$ & $11 \cdot 1$ & $(1 \cdot 0)$ & $20 \cdot 0$ & $(1 \cdot 3)$ \\
\hline \multicolumn{11}{|l|}{ Males $(N=619)$} \\
\hline Subthreshold MDD & $4 \cdot 4$ & $(0 \cdot 9)$ & $2 \cdot 5$ & $(0 \cdot 7)$ & $1 \cdot 0$ & $(0 \cdot 4)$ & $1 \cdot 8$ & $(0 \cdot 7)$ & $4 \cdot 7$ & $(0 \cdot 9)$ \\
\hline MDD & $5 \cdot 4$ & $(1 \cdot 1)$ & $2 \cdot 4$ & $(0 \cdot 7)$ & $3 \cdot 7$ & $(0 \cdot 8)$ & $4 \cdot 7$ & $(1 \cdot 0)$ & $9 \cdot 1$ & $(1 \cdot 3)$ \\
\hline Mild & $0 \cdot 8$ & $(0 \cdot 4)$ & $0 \cdot 5$ & $(0 \cdot 3)$ & $1 \cdot 7$ & $(0 \cdot 6)$ & $2 \cdot 6$ & $(0 \cdot 7)$ & $2 \cdot 5$ & $(0 \cdot 7)$ \\
\hline Moderate & $2 \cdot 3$ & $(0 \cdot 7)$ & $1 \cdot 0$ & $(0 \cdot 4)$ & $1 \cdot 2$ & $(0 \cdot 5)$ & $1 \cdot 2$ & $(0 \cdot 5)$ & $3 \cdot 4$ & $(0 \cdot 8)$ \\
\hline Severe & $2 \cdot 4$ & $(0 \cdot 8)$ & $1 \cdot 0$ & $(0 \cdot 5)$ & $0 \cdot 7$ & $(0 \cdot 4)$ & $0 \cdot 8$ & $(0 \cdot 4)$ & $3 \cdot 2$ & $(0 \cdot 9)$ \\
\hline Dysthymia & $1 \cdot 1$ & $(0 \cdot 4)$ & $0 \cdot 9$ & $(0 \cdot 3)$ & $1 \cdot 2$ & $(0 \cdot 5)$ & $1 \cdot 4$ & $(0 \cdot 5)$ & $2 \cdot 3$ & $(0 \cdot 6)$ \\
\hline Any (including subthreshold) & $10 \cdot 7$ & $(1 \cdot 4)$ & $5 \cdot 8$ & $(1 \cdot 0)$ & $4 \cdot 1$ & $(0 \cdot 9)$ & $7 \cdot 5$ & $(1 \cdot 2)$ & $14 \cdot 8$ & $(1 \cdot 6)$ \\
\hline \multicolumn{11}{|l|}{ Females $(N=609)$} \\
\hline Subthreshold MDD & $6 \cdot 1$ & $(1 \cdot 0)$ & $4 \cdot 6$ & $(0 \cdot 9)$ & $3 \cdot 1$ & $(0 \cdot 7)$ & $4 \cdot 1$ & $(0 \cdot 8)$ & $7 \cdot 9$ & $(1 \cdot 2)$ \\
\hline MDD & $8 \cdot 0$ & $(1 \cdot 2)$ & $4 \cdot 5$ & $(0 \cdot 9)$ & $7 \cdot 5$ & $(1 \cdot 2)$ & $8 \cdot 9$ & $(1 \cdot 3)$ & $15 \cdot 4$ & $(1 \cdot 6)$ \\
\hline Mild & $1 \cdot 4$ & $(0 \cdot 6)$ & $0 \cdot 9$ & $(0 \cdot 5)$ & 1.9 & $(0 \cdot 6)$ & $2 \cdot 2$ & $(0 \cdot 6)$ & $3 \cdot 0$ & $(0 \cdot 8)$ \\
\hline Moderate & $2 \cdot 5$ & $(0 \cdot 7)$ & $1 \cdot 2$ & $(0 \cdot 4)$ & $2 \cdot 8$ & $(0 \cdot 7)$ & $3 \cdot 3$ & $(0 \cdot 8)$ & $5 \cdot 0$ & $(0 \cdot 9)$ \\
\hline Severe & $4 \cdot 0$ & $(0 \cdot 9)$ & $2 \cdot 4$ & $(0 \cdot 7)$ & $2 \cdot 8$ & $(0 \cdot 7)$ & $3 \cdot 3$ & $(0 \cdot 8)$ & $7 \cdot 3$ & $(1 \cdot 2)$ \\
\hline Dysthymia & $2 \cdot 3$ & $(0 \cdot 6)$ & $2 \cdot 3$ & $(0 \cdot 6)$ & $2 \cdot 4$ & $(0 \cdot 7)$ & $2 \cdot 8$ & $(0 \cdot 8)$ & $4 \cdot 7$ & $(0.9)$ \\
\hline Any (including subthreshold) & $15 \cdot 3$ & $(1 \cdot 6)$ & $10 \cdot 2$ & $(1 \cdot 3)$ & $10 \cdot 0$ & $(1 \cdot 3)$ & $14 \cdot 8$ & $(1 \cdot 6)$ & $25 \cdot 3$ & $(1.9)$ \\
\hline
\end{tabular}

LT, lifetime.

Because of the hierarchical nature of subthreshold and threshold MDD, and of mild, moderate and severe MDD, for these categories the cumulative lifetime incidence may not equal the sum of the lifetime prevalence at baseline plus the incidence.

prevalence estimate of $8.0 \%$. The overall 20 month incidence rate was $7 \cdot 1 \%$, with a relatively higher incidence of dysthymia and MDD than of subthreshold MDD. In part, the stronger increase of MDD as compared to subthreshold MDD during the follow-up period may be due to the fact that baseline subthreshold MDD could develop into follow-up MDD, but not vice versa. By prorating the 20 -month incidence, we can get a rough estimation of the 12-month incidence, which is $4.3 \%$ overall (subthreshold MDD $1.3 \%$, MDD $3 \cdot 4 \%$, dysthymia $1 \cdot 1 \%$ ). The female-to-male ratio of any depressive disorder increased from $1.4\left(\chi_{1}^{2}=5.69, P=\right.$ $0 \cdot 02)$ at baseline to $1 \cdot 7\left(\chi_{1}^{2}=20 \cdot 9, P<0 \cdot 01\right)$ at follow-up. Hence overall, depression was more prevalent among females, and the gender difference seemed to increase between baseline and follow-up. The overall cumulative incidence at follow-up indicates that $20.0 \%$ of the sample had fulfilled criteria for at least one (subthreshold) depressive condition, with a preponderance of MDDs, both in males $(9 \cdot 1 \%$ of a total of $14.8 \%)$ and in females $(15.4 \%$ of a total of $25.3 \%$ ). It is remarkable that only a minority of the MDDs were mild, and over $40 \%$ were severe, i.e. had several symptoms in excess of those required for the diagnosis and marked interference with occupational or social functioning. Despite the young age of the sample, $12 \%$ of the MDDs were recurrent (males $8 \%$, females $15 \%, \chi_{1}^{2}=1 \cdot 47, P=0 \cdot 22$ ).

\section{Age of onset}

Fig. 1 represents cumulative hazards, for both baseline and follow-up findings. The baseline and follow-up curves largely overlap before the age of 14, suggesting considerable consistency of the age-of-onset reports (Wittchen et al. 1998d). The cumulative hazard functions of all three 
Subthreshold depressive disorder
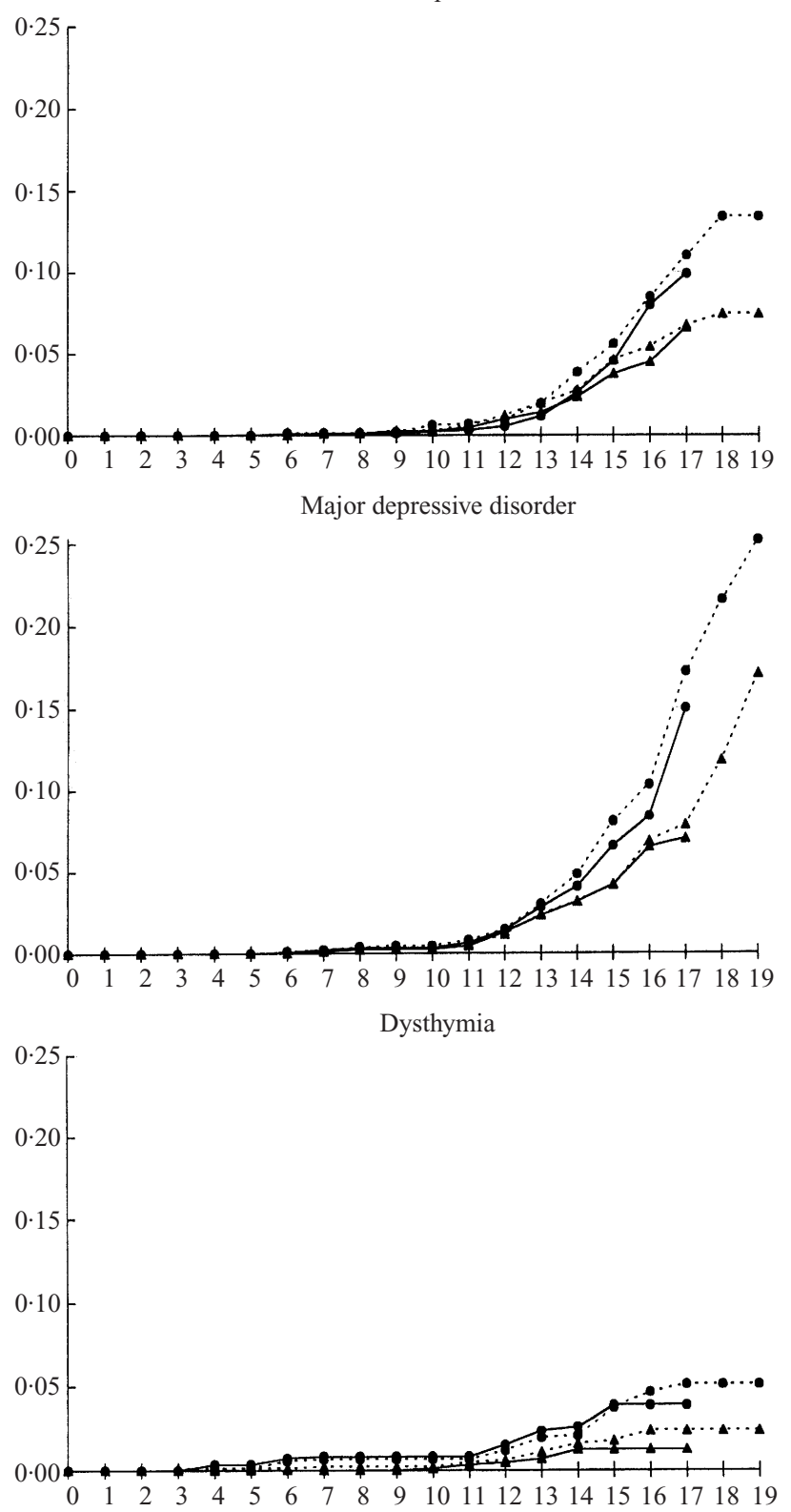

FIG. 1. Age of onset curves (cumulative incidences) of depressive conditions, by gender $(\boldsymbol{\Lambda}$, male; $\boldsymbol{\bullet}$, female), baseline $(-)$ and follow-up (-----) estimates.

diagnoses indicate consistently that onset prior to the age of 12 is rare, with a fairly strong and steadily rising cumulative incidence after the age of 13 for MDD. The increase in gender differences was examined by repeated measures analysis of variance (ANOVA) on the lifetime rates of depression, with gender as betweensubjects factor and age as within-subjects factor (using unweighted data). Although ANOVA assumes normally distributed variables, it produces reasonably accurate probability statements for dichotomous data (Winer, 1971). The 
Table 3. Clinical outcome characteristics at follow-up among those with a lifetime diagnosis of depression at baseline, weighted estimates $(\mathrm{N}=1228)$

\begin{tabular}{|c|c|c|c|c|c|c|c|c|}
\hline \multirow[b]{3}{*}{ Outcome at follow-up } & \multicolumn{8}{|c|}{ Diagnosis at baseline } \\
\hline & \multicolumn{2}{|c|}{$\begin{array}{l}\text { No. depr. } \\
\text { condition } \\
(N=1069)\end{array}$} & \multicolumn{2}{|c|}{$\begin{array}{l}\text { Subthr. MDD } \\
\quad(N=65)\end{array}$} & \multicolumn{2}{|c|}{$\begin{array}{l}\text { MDD } \\
(N=82)\end{array}$} & \multicolumn{2}{|c|}{$\begin{array}{l}\text { Dysthymia } \\
(N=21)\end{array}$} \\
\hline & $\%$ & (S.E.) & $\%$ & (S.E.) & $\%$ & (S.E.) & $\%$ & (S.E.) \\
\hline \multicolumn{9}{|l|}{$\begin{array}{l}\text { Number of periods } \dagger \text { with depressed mood, } \\
\text { lack of energy or loss of interest }\end{array}$} \\
\hline 1 & $21 \cdot 1$ & $(1 \cdot 4)$ & $32 \cdot 5^{*}$ & $(6 \cdot 7)$ & $36 \cdot 7 *$ & $(6 \cdot 1)$ & $45 \cdot 9 *$ & $(10 \cdot 9)$ \\
\hline$>1$ & $7 \cdot 8$ & $(0 \cdot 9)$ & $19 \cdot 7^{*}$ & $(5 \cdot 3)$ & $26 \cdot 1 *$ & $(5 \cdot 8)$ & $39 \cdot 0^{*}$ & $(10 \cdot 7)$ \\
\hline \multicolumn{9}{|l|}{ Impairment due to depr. symptoms: } \\
\hline Some & $9 \cdot 1$ & $(1 \cdot 0)$ & $17 \cdot 2^{*}$ & $(4 \cdot 9)$ & $19 \cdot 8^{*}$ & $(5 \cdot 4)$ & $15 \cdot 3 *$ & $(6 \cdot 7)$ \\
\hline Considerable & $7 \cdot 3$ & $(0 \cdot 9)$ & $23 \cdot 7^{*}$ & $(5 \cdot 7)$ & $29 \cdot 3 *$ & $(5 \cdot 8)$ & $45 \cdot 6^{*}$ & $(10 \cdot 9)$ \\
\hline \multicolumn{9}{|l|}{ Days unable to work $\S$ in last 4 weeks } \\
\hline At least one & $2 \cdot 5$ & $(0 \cdot 5)$ & $8 \cdot 8^{*}$ & $(3 \cdot 2)$ & $9 \cdot 9 *$ & $(3 \cdot 5)$ & $31 \cdot 4^{*}$ & $(10 \cdot 3)$ \\
\hline \multicolumn{9}{|l|}{ 12-month diagnosis at follow-up } \\
\hline Completely remitted/no depr. symptoms & $81 \cdot 3$ & $(1 \cdot 3)$ & $53 \cdot 8^{*}$ & $(6 \cdot 7)$ & $42 \cdot 7 *$ & $(6 \cdot 3)$ & $33 \cdot 3 *$ & $(10 \cdot 3)$ \\
\hline Partially remitted/symptomatic & $10 \cdot 8$ & $(1 \cdot 1)$ & $20 \cdot 0$ & $(5 \cdot 4)$ & $19 \cdot 5^{*}$ & $(4 \cdot 8)$ & $14 \cdot 3$ & $(6 \cdot 7)$ \\
\hline Subthreshold MDD & $2 \cdot 2$ & $(0 \cdot 4)$ & $4 \cdot 6$ & $(2 \cdot 9)$ & $11 \cdot 1 *$ & $(4 \cdot 6)$ & $4 \cdot 8$ & $(3 \cdot 3)$ \\
\hline MDD & $4 \cdot 9$ & $(0.7)$ & $18 \cdot 8^{*}$ & $(5 \cdot 3)$ & $18 \cdot 3 *$ & $(4 \cdot 8)$ & $28 \cdot 6^{*}$ & $(9 \cdot 9)$ \\
\hline Dysthymia & $1 \cdot 3$ & $(0 \cdot 4)$ & $4 \cdot 6^{*}$ & $(2 \cdot 5)$ & $9 \cdot 8^{*}$ & $(4 \cdot 0)$ & $23 \cdot 8^{*}$ & $(9 \cdot 7)$ \\
\hline Bipolar disorder & $0 \cdot 9$ & $(0 \cdot 3)$ & $3 \cdot 1$ & $(1.8)$ & $3 \cdot 7 *$ & $(2 \cdot 6)$ & $0 \cdot 0$ & $(0 \cdot 0)$ \\
\hline Suicidal ideation & 3.6 & $(0 \cdot 6)$ & $11 \cdot 5^{*}$ & $(4 \cdot 2)$ & $10 \cdot 4 *$ & $(3 \cdot 5)$ & $25 \cdot 5^{*}$ & $(10 \cdot 2)$ \\
\hline Suicide attempt & $0 \cdot 7$ & $(0 \cdot 3)$ & $2 \cdot 9$ & $(2 \cdot 8)$ & $4 \cdot 4^{*}$ & $(2 \cdot 7)$ & $17 \cdot 3^{*}$ & $(9 \cdot 5)$ \\
\hline Received professional help & $3 \cdot 4$ & $(0 \cdot 6)$ & $11 \cdot 9 *$ & $(4 \cdot 4)$ & $7 \cdot 6$ & $(3 \cdot 0)$ & $22 \cdot 5^{*}$ & $(6 \cdot 1)$ \\
\hline
\end{tabular}

$\dagger$ Periods of at least 2 weeks, with at least one of these symptoms present almost every day, during most part of the day.

* Both overall and social-role-specific impairment, which could be scored as none, a little, some, and a lot (= considerable).

$\S$ Number of days unable to do daily activities (school, work) because of psychological symptoms.

* Significant $(P<0.05)$ difference with the group with no depressive condition at baseline, based on logistic regression analysis.

ANOVA yielded significant main and interaction effects for gender and age (linear contrast) for all depressive conditions (subthreshold MDD, gender $F(1,1226)=7 \cdot 0, P<0 \cdot 01$, age $F(1,1226)=57.6, \quad P<0.01$; interaction $F(1$, $1226)=8 \cdot 9, P<0.01 ;$ MDD gender $F(1,1226)$ $=17.4, P<0.01$, age $F(1,1226)=96.2, P<$ $0 \cdot 01$, interaction $F(1,1226)=12 \cdot 1, \quad P<0.01$; dysthymia, gender $F(1,1226)=5 \cdot 0, P=0 \cdot 03$, age $F(1,1226)=16 \cdot 0, P<0 \cdot 01$, interaction $F(1$, 1226) $=5 \cdot 8, P=0 \cdot 02$ ). The coefficients of the interaction parameters indicated that differences between males and females increased with age. At baseline, there were no significant gender differences in age of onset for subthreshold MDD ( $t$ value, $0.64, P=0.52)$, or for MDD $(t$ $=0.73, P=0.47)$ or dysthymia $(t=1.49, P=$ $0 \cdot 15$ ). At follow-up, however, the gender differences in the age of onset of MDD reached statistical significance (mean age of onset males $17 \cdot 3$, females $16 \cdot 5, t=2 \cdot 13, P=0 \cdot 04)$.

\section{Clinical outcome characteristics}

The probability of unfavourable outcomes was significantly elevated in cases with any baseline depression as compared to those unaffected at baseline (Table 3). In general, MDD cases had more unfavourable outcomes than subthresholdMDD cases, and the outcome pattern of dysthymia was consistently the least favourable one. All three groups were significantly more likely than those unaffected at baseline to have additional or continued episodes of depressed mood, lack of energy or loss of interest: $52 \cdot 2 \%$ of the subthreshold MDD group, $62.8 \%$ of those with MDD and $84.9 \%$ of the dysthymia cases as compared to only $29.0 \%$ in the unaffected group reported having had at least one such episode during follow-up. Besides, all baseline diagnostic groups were (significantly) more likely to report considerable psychosocial impairments due to depressive symptoms, and 
Table 4. Depression (lifetime) at baseline versus depressive status (12-month) at follow-up. Total percentages, and conditional probabilities (counts in parentheses), weighted estimates

\begin{tabular}{|c|c|c|c|c|c|}
\hline & \multicolumn{5}{|c|}{ Depression symptoms and diagnostic status at follow-up } \\
\hline & None & Symptomatic & Subthreshold & Threshold & Total \\
\hline \multicolumn{6}{|c|}{$\begin{array}{l}\text { Depression symptoms and } \\
\text { diagnostic status at baseline }\end{array}$} \\
\hline \multicolumn{6}{|c|}{ None } \\
\hline$\%$ of total & $63.5 \%$ & $8 \cdot 1 \%$ & $1 \cdot 4 \%$ & $3 \cdot 8 \%$ & $76 \cdot 9 \%$ \\
\hline $\begin{array}{l}\text { Cond. prob. } \\
(N)\end{array}$ & $\begin{array}{l}82 \cdot 6 \% \\
(780)\end{array}$ & $10 \cdot 6 \%$ & $1 \cdot 8 \%$ & $\begin{array}{l}5 \cdot 0 \% \\
(47)\end{array}$ & $100 \%$ \\
\hline \multicolumn{6}{|l|}{ Symptomatic } \\
\hline$\%$ of total & $7 \cdot 2 \%$ & $1 \cdot 2 \%$ & $0 \cdot 2 \%$ & $1 \cdot 4 \%$ & $10 \cdot 1 \%$ \\
\hline Cond. prob. & $71 \cdot 8 \%$ & $12 \cdot 1 \%$ & $2 \cdot 4 \%$ & $13 \cdot 7 \%$ & $100 \%$ \\
\hline \multirow{2}{*}{\multicolumn{6}{|c|}{ Subthreshold }} \\
\hline$\%$ of total & & $1.0 \%$ & $0.2 \%$ & & \\
\hline Cond. prob. & $56 \cdot 7 \%$ & $20 \cdot 0 \%$ & $5.0 \%$ & $18 \cdot 3 \%$ & $100 \%$ \\
\hline$(N)$ & (34) & (12) & (3) & (11) & $(60)$ \\
\hline \multicolumn{6}{|l|}{ Threshold } \\
\hline$\%$ of total & $3 \cdot 4 \%$ & $1.5 \%$ & $0.7 \%$ & $2 \cdot 4 \%$ & $8 \cdot 1 \%$ \\
\hline Cond. prob. & $42 \cdot 0 \%$ & $19 \cdot 0 \%$ & $9 \cdot 0 \%$ & $30 \cdot 0 \%$ & $100 \%$ \\
\hline$(N)$ & (42) & (19) & (9) & (30) & (99) \\
\hline \multicolumn{6}{|l|}{ Total } \\
\hline$\%$ of total & $77.0 \%$ & $11.9 \%$ & $2 \cdot 6 \%$ & $8.6 \%$ & $100 \%$ \\
\hline$(N)$ & $(945)$ & (146) & (32) & $(105)$ & (1228) \\
\hline
\end{tabular}

had more work-loss days in the month before follow-up. Complete remissions, defined as not having endorsed any of the depression stem questions (feeling depressed or lost interest for 2 weeks or more during the 12 months preceding the follow-up interview), were found in only $53.8 \%$ of the subthreshold, and $42 \cdot 7 \%$ (MDD) and $33.3 \%$ (dysthymia) of the threshold baseline cases. Baseline dysthymia cases had the least favourable outcome; $28.6 \%$ developed an MDD and $23.8 \%$ met full dysthymia criteria again at follow-up. A baseline diagnosis of any depressive condition also significantly increased the probability of reporting suicidal ideation and suicide attempts. The probability of suicidal ideation was highest $(25.5 \%)$ for those with a baseline diagnosis of dysthymia; $17 \cdot 3 \%$ of the baseline dysthymia cases actually attempted suicide. Despite this unfavourable picture, only 7.6 $12.5 \%$ of baseline depression cases reported having received any type of professional help (including a wide range of services such as help services for children and parents, school psychologists, general practitioners and telephone help services, which are specifically probed in the health service utilization section of the MCIDI), irrespective of type, duration or adequacy. Among those with dysthymia, the outcomes of persons with double depression, i.e. both dysthymia and MDD, was particularly unfavourable. But also pure baseline dysthymia cases (without co-morbid MDD, $N=15$ ) were more likely to experience other episodes with depressive symptoms $(78.9 \%)$, to report some or considerable impairment $(50.0 \%)$, to be unable to do daily activities $(26.7 \%)$, or to consider $(28.6 \%)$ or attempt $(28.6 \%)$ suicide than other depressive conditions. Compared to double depression, however, pure dysthymia cases had a higher probability of complete remission $(46 \cdot 7 \%)$.

\section{Baseline by follow-up depression diagnostic status across boundaries of specific disorders}

Since dysthymia overlaps with (subthreshold) MDD, Table 4 cross-tabulates the overall outcome and stability findings on four levels of depression symptoms and diagnostic status, across boundaries of specific depressive disorders, at baseline and at follow-up. The first column in Table 4 indicates that the conditional probability of being well at follow-up, thus of reporting no significant signs of depression, decreased monotonically from $82.6 \%$ among asymptomatic baseline respondents, over $71.8 \%$ in symptomatic and $56.7 \%$ in subthreshold baseline cases, to a low of $42.0 \%$ among threshold baseline cases. Similarly, the con- 
ditional probability of being a threshold case of depression at follow-up, increased from a low of $5.0 \%$ in the asymptomatic baseline group to a high of $30.0 \%$ in the baseline threshold group. Similar systematic patterns can be seen for the categories in between.

The stability of being at least symptomatic was $41 \cdot 1 \%$. Subthreshold MDD was the least stable diagnosis; only $5.0 \%$ of the respondents with a baseline subthreshold MDD had the same diagnosis at follow-up. Baseline symptomatic depression increased the likelihood of a follow-up threshold diagnosis about 2.5-fold, compared to respondents without any baseline depressive symptomatology. It is noteworthy that the probability of change between baseline and follow-up increased with increasing length of follow-up interval; $30 \%$ of the probands with an interval up to 19 months changed between baseline and follow-up, versus $35 \%$ of the probands with a follow-up period of 20 months or more. However, the average length of followup did not differ much between the various levels of depressive symptomatology at baseline (none, $19 \cdot 6$ months; symptomatic, 20.0 months; subthreshold, 19.7 months; threshold, 20.3 months) and the effect of length of follow-up period on the probability of change was the same for all categories (no significant interaction effects). We further examined whether the likelihood of a (subthreshold or threshold) depression at follow-up, given a depression at baseline, was related to gender, age, or severity of depression at baseline. Although the results suggest $(P<0 \cdot 10)$ that depression was more persistent for older respondents with a higher severity at baseline, none of these factors predicted depression at a statistically significant level.

\section{Subthreshold depression: not meeting criterion A versus not meeting criterion $C$}

Subthreshold MDD was defined as falling short of either the DSM-IV criterion of at least five symptoms (Subthresh/Sx), or the criterion of significant impairment (Subthresh/Imp). Subthresh/Sx (i.e. four instead of at least five symptoms) was relatively more frequent at baseline measurement (12-month prevalence $2.4 \%$ versus $1.1 \%$ for Subthresh/Imp), whereas Subthresh/Imp was more prevalent at follow-up (12-month prevalence $1.6 \%$ versus $1.3 \%$ for
Subthresh/Sx). The cumulative lifetime incidences were about equal (Subthresh/Sx, 3.1\%; Subthresh/Imp, 3.3\%). Subthresh/Sx did not differ from Subthresh/Imp with regard to mean age of onset (baseline, $t=-0.38, P=0.71$; follow-up $t=1 \cdot 01, P=0 \cdot 32$ ). However, persons not meeting the criterion of at least five symptoms at baseline (Subthresh/Sx) had significantly more often one or more periods of depressed mood $\left(65.0 \%\right.$ versus $32.0 \%, x_{1}^{2}=$ $6.72, P=0.01$ ), and considerable impairment $\left(32.5 \%\right.$ versus $\left.8.0 \%, \chi_{1}^{2}=5.20, P=0.02\right)$ between baseline and follow-up. Furthermore, fewer of the Subthresh/Sx-group had remitted completely $\left(40.0 \%\right.$ versus $76.0 \%, \chi_{1}^{2}=8.02, P$ $<0.01)$ and more of them had a diagnosis of $\operatorname{MDD}\left(30.0 \%\right.$ versus $\left.4.0 \%, \chi_{1}^{2}=6.50, P=0.01\right)$ at follow-up. In fact, in terms of clinical outcome characteristics Subthresh/Sx depressions closely resembled threshold MDD: there were no significant differences between the two groups on either of the clinical outcome characteristics listed in Table 3. On the other hand, persons not meeting the impairment-criterion (Subthresh/ Imp) did not differ significantly from people with no depressive condition on any of the clinical outcome characteristics. Similarly, the stability estimates for Subthresh/Sx were completely comparable to those for threshold depression, and the estimates for Subthresh/Imp were of the order of the magnitude of the estimates for no and symptomatic depression.

\section{DISCUSSION}

The main aim of this paper was to estimate prevalence and incidence of several depressive conditions, and to investigate age-of-onset characteristics and 20-month outcome. Largely consistent with other studies, our results reveal that depressive disorders (MDD and dysthymia) as defined by M-CIDI/DSM-IV criteria are quite prevalent in adolescents, affecting about $14 \%$ of the sample and $20 \%$ if including subthreshold MDD. It is noteworthy that our estimated rates for MDD and dysthymia are well within the range of those found in a number of other recent population-based studies among adolescents and young adults, summarized in Table 5 .

Although we could speculate to what degree the differences in rates might be a reflection of 
Table 5. Prevalence and incidence rates of major depression and dysthymia in a number of population-based studies

\begin{tabular}{|c|c|c|c|c|}
\hline Study, area & Age & Time frame & MDD & Dysthymia \\
\hline EDSP, Munich, Germany (this paper) & $15-19$ & Lifetime & $12 \cdot 2 \%$ & $3.5 \%$ \\
\hline OADP, Oregon (Lewisohn et al. 1993) & $15-19$ & Lifetime & $24 \cdot 0 \%$ & $3.0 \%$ \\
\hline NCS, USA (Kessler et al. 1994, Blazer et al. 1994) & $15-24$ & Lifetime & $15 \cdot 7 \%$ & - \\
\hline USA (Whittaker et al. 1990) & $14-17$ & Lifetime & $4.0 \%$ & $4 \cdot 0 \%$ \\
\hline EDSP, Munich Germany (this paper) & $15-19$ & 12-month & $6.8 \%$ & $2 \cdot 1 \%$ \\
\hline DMHDS, Dunedin, New Zealand (Feehan et al. 1994) & 18 & 12-month & $16 \cdot 7 \%$ & - \\
\hline NCS, USA (Kessler et al. 1994) & $15-24$ & 12 -month & $12 \cdot 8 \%$ & - \\
\hline OHS, Ontario (Offord et al. 1996) & $15-24$ & 12-month & $5 \cdot 1 \%$ & $3 \cdot 2 \%$ \\
\hline CHDS, Christchurch, New Zealand (Fergusson et al. 1993) & 15 & 12 -month & $4 \cdot 2 \% *$ & $0.4 \% *$ \\
\hline The Netherlands (Verhulst et al. 1997) & $13-18$ & 6-month & $2 \cdot 8 \% *$ & $1.5 \% *$ \\
\hline EDSP, Munich, Germany (this paper) & $15-19$ & 12-month incidence & $3.4 \% \dagger$ & $1 \cdot 1 \% \dagger$ \\
\hline OADP, Oregon (Lewinsohn et al. 1993) & $15-19$ & 12-month incidence & $5 \cdot 7 \%$ & $0 \cdot 1 \%$ \\
\hline
\end{tabular}

* Based on adolescents' self-reports.

$\dagger$ Estimated by prorating the 20-month incidence.

ESCP, Early Developmental Stages of Psychopathology; OADP, Oregon Depression Project; NCS, National Comorbidity Survey; DMHDS, Dunedin Multidisciplinary Health and Development Study; OHS, Ontario Health Survey; CHDS, Christchurch Health and Development Study.

variations in risk constellations in the respective populations, we rather assume that they are largely a result of design features, such as the sample selection, age distribution and diagnostic interview. We also confirm that depressive disorders in this age group: $(a)$ are more frequent in females and that this difference gets larger with increasing age; $(b)$ rarely start before the age of 13; and $(c)$ are poorly treated, even in a comprehensive health care system offering any type of medical and psychological therapy free of charge. The low treatment rates found in this study are consistent with reports from the UK (Goodyer \& Cooper, 1993), USA (Whittaker et al. 1990), Canada (Links et al. 1989) and New Zealand (Fergusson et al. 1993). Comparison of several age groups with respect to treatment rates for MDD in Germany revealed that the probability of treatment increased with age, treatment rates were low overall, but particularly low in young people (Wittchen et al. 1999).

Beyond previous studies, we demonstrated that: $(a)$ only few $(23 \%)$ MDDs in adolescence are mild in terms of number and severity of symptoms, whereas many $43 \%$ are classified as severe; and that (b) subthreshold MDD has almost identical age-of-onset characteristics as MDD (irrespective of whether the symptoms did not meet criterion A or criterion C). Hence, although we did find that subthreshold disorders were relatively more frequent in younger respondents, we failed to confirm the hypothesis that they are more likely to have an onset in childhood. Both threshold and subthreshold disorders are relatively rare before the age of 13 , affecting only about $2 \%$ of the population in childhood.

\section{Age of onset}

We found consistently that onset prior to the age of 12 was relatively rare, with a fairly strong and steadily rising cumulative incidence after the age of 13 for MDD. The age-of-onset curves of MDD largely resemble those presented by Lewinsohn et al. (1992), except for the scale of the $Y$-axis: our cumulative incidences are considerably lower. We estimated separate age-ofonset curves for baseline and follow-up reports. The curves largely overlapped before the age of 14 , suggesting a sufficient reliability of the ageof-onset information in terms of consistency of report. This is better than might be expected on the basis of previous reports, which suggested that recall of dates of onset of symptoms over periods of more than a few months may be subject to a great deal of error (Angold et al. 1996). The high consistency of the age-of-onset information given by the respondent over a period of more than one and a half years may be a result of the detailed way it is assessed in the M-CIDI, which uses cognitive aids to stimulate memory search for the first occurrence of key features of the condition and separate summary questions to assess when the respondent met the 
full set of diagnostic criteria (Wittchen et al. 1998d).

\section{Natural course}

Given the stereotype that adolescent depressive disorders are frequently mild and short-lived, our results regarding the natural course of adolescent depression revealed an unexpectedly unfavourable outcome pattern. Complete remission was found in only $54 \%$ of those with subthreshold MDD, $43 \%$ of those with threshold MDD and $33 \%$ of the baseline dysthymia cases. Baseline dysthymia cases had the least favourable outcome; $29 \%$ developed a MDD and 24\% met full dysthymia criteria again at follow-up. Persistence of depression at follow-up seemed to be related to higher age and severity of depression at baseline. These findings are similar to those found in a sample of 8-16year-old mental health care out-patients (Goodyer et al. 1997). The unfavourable outcome of cases with dysthymia is in line with previous findings (e.g. AACAP, 1998). It is notable that this outcome was only partly influenced by cases with double depression, who had the least favourable outcome pattern of all, and that even dysthymic adolescents without MDD had low $(<50 \%)$ chances of recovery, frequently $(50 \%)$ reported psychosocial impairments due to depressive symptoms during follow-up, as well as suicide attempts $(29 \%)$. One possible explanation may be that earlyonset dysthymic disorder is a forerunner of recurrent affective illness (Kovacs et al. 1994). Our data support the idea that dysthymia is milder in terms of symptomatology but has a more chronic course (Klein et al. 1998) and higher impairment rates (Whittaker et al. 1990), suggesting that duration may be at least at important as symptom severity.

\section{Subthreshold forms of depression}

In this study, the outcome of adolescents with four depressive symptoms and impairments was just as unfavourable as the outcome of those with five symptoms or more (i.e. MDD). When the symptoms did not meet the impairment (or distress) criterion, the outcome was not or hardly more unfavourable than that of persons without a depressive condition. Hence, our results support the recommendations by Roberts et al. (1998) and Costello et al. (1996b) to use both symptom and impairment criteria when determining caseness. On the other hand, the Acriterion for MDD, requiring at least five symptoms, seems to be arbitrary, at least in this adolescent sample. Strict application of this rule might lead to underestimation of the amount of severe depressive symptomatology in adolescents.

This study has noteworthy limitations. The interpretation of our findings is limited by the fact that we did not report the effect of comorbidity with other DSM-IV disorders on the probability, severity and persistence of depression. We acknowledge that co-morbidity may largely affect the course and outcome of adolescent depression (e.g. Kovacs et al. 1989; Harrington et al. 1991; Birmaher et al. 1996; Goodyer et al. 1997). We also refrained from reporting any details on (putative) risk factor of adolescent depression. The complexity of these mechanisms requires them to be dealt with in a separate paper. The information gathered in this study was obtained exclusively from the adolescents themselves. Since many parents of 14-19-year-olds will not be completely informed about their childrens' thoughts and emotions, adolescent self-report is essential for the study of emotional disorders (Whittaker et al. 1990). Although additional information from parents and teachers may provide further insight, parent reports and adolescent self-reports of affective disorders have been found to have little overlap between them (Fleming et al. 1989; Cantwell et al. 1996; Verhulst et al. 1997) and are hence difficult to interpret. We feel confident about our procedure because M-CIDI diagnoses have been found to be as reliable and valid in adolescent and young adults as in older respondents (Wittchen \& Pfister, 1997).

Our data suggest that DSM-IV MDD and dysthymia are frequent adolescent disorders, with an estimated lifetime cumulative incidence of $14 \%$, that they are rare before the age of 13 , that more than half of them persist or remit only partly during a 20-month follow-up period, and that only a minority is treated professionally. Although this study did not investigate the resulting impairment in various roles and domains in detail, the indicators used point to the potential importance of these disorders in a key developmental phase of life, in which critical choices are made in terms of personal relation- 
ships and professional career. To what extent these choices are affected by depressive symptomatology should be studied in the future. Furthermore, continued research emphasis should be given to subthreshold forms of MDD and their implications for optimal diagnostic algorithms for adolescents.

We would like to thank Johan Ormel for his helpful comments.

\section{REFERENCES}

American Academy of Child and Adolescent Psychiatry (1998) Practice parameters for the assessment and treatment of children and adolescents with depressive disorder. Journal of the American Academy of Child and Adolescent Psychiatry 37 (suppl.), 63S-83S.

American Psychiatric Association (1994). Diagnostic and Statistical Manual of Mental Disorders, 4th edn. APA: Washington, DC.

Angold, A., Prendergast, M., Cox, A., Harrington, M., Simonoff, E. \& Rutter, M. (1995). The Child and Adolescent Psychiatric Assessment (CAPA). Psychological Medicine 25, 739-753.

Angold, A., Erkanli, A., Costello, E. J. \& Rutter, M. (1996). Precision, reliability and accuracy in the dating of symptom onsets in child and adolescent psychopathology. Journal of Child Psychology and Psychiatry 37, 657-664.

Angold, A., Costello, E. J. \& Worthman, C. M. (1998). Puberty and depression: the roles of age, pubertal status and pubertal timing. Psychological Medicine 28, 51-61.

Birmaher, B., Ryan, N. D., Williamson, D. E., Brent, D. A., Kaufman, J., Dahl, R. E., Perel, J. \& Nelson, B. (1996).Childhood and adolescent depression: a review of the past 10 years. Part I. Journal of the American Academy of Child and Adolescent Psychiatry 35, 1427-1439.

Blazer, D. G., Kessler, R. C., McGonagle, K. A. \& Swartz, M. S. (1994). The prevalence and distribution of major depression in a national community sample: the national comorbidity survey. American Journal of Psychiatry 151, 979-986.

Burke, K. C., Burke, J. D., Regier, D. A. \& Rare, R. D. (1990). Age at onset of selected mental disorders in five community populations Archives of General Psychiatry 47, 511-518.

Cantwell, D. P., Lewinsohn, P. M., Rohde, P. \& Seeley, J. R. (1996). Correspondence between adolescent report and parent report of psychiatric diagnostic data. Journal of the American Academy of Child and Adolescent Psychiatry 36, 610-619.

Cooper, P. J. \& Goodyer, I. (1993). A community study of depression in adolescent girls. I: Estimates of symptom and syndrome prevalence. British Journal of Psychiatry 163, 369-374.

Costello, E. J., Angold, A., Burns, B. J., Stangl, D. K., Tweed, D. L., Erkanli, A. \& Worthman, C. M. (1996a). The Great Smokey Mountains Study of youth: goals, design, methods, and the prevalence of DSM-III-R disorders. Archives of General Psychiatry 53, 1129-1136.

Costello, E. J., Angold, A., Burns, B. J., Erkanli, A., Stangl, D. K. \& Tweed, D. L. (1996b). The Great Smokey mountains Study of youth: functional impairment and serious emotional disorder. Archives of General Psychiatry 53, 1137-1143.

Feehan, M., McGee, R., Nada Raja, S. \& Williams, S. M. (1994). DSM-III-R disorders in New Zealand 18-year-olds Australian and New Zealand Journal of Psychiatry 28, 87-99.

Ferguson, D. M., Horwood, L. J. \& Lynsley, M. T. (1993). Prevalence and comorbidity of DSM-III-R diagnoses in a birth cohort of 15 year olds. Journal of the American Academy of Child and Adolescent Psychiatry 32, 1127-1134.
Fleming, J. E. \& Offord, D. R. (1990). Epidemiology of childhood depressive disorder: a critical review. Journal of the American Academy of Child and Adolescent Psychiatry 29, 571-580.

Fleming, J. E., Offord, D. R. \& Boyle, M. H. (1989). Prevalence of childhood and adolescent depression in the community. Ontario Child Health Study. British Journal of Psychiatry 155, 647-654.

Ge, X., Lorenz, F. O., Conger, R. D., Elder, G. H. \& Simons, R. L. (1994). Trajectories of stressful life events and depressive symptoms during adolescence. Developmental Psychology 30, 467-483.

Goodyer, I. \& Cooper, P. J. (1993). A community study of depression in adolescent girls. II: The clinical features of identified disorder. British Journal of Psychiatry 163, 374-380.

Goodyer, I. M., Herbert, J., Secher, S. M. \& Pearson, J. (1997). Short-term outcome of major depression. I. Comorbidity and severity at presentation as predictors of persistent disorder. Journal of the American Academy of Child and Adolescent Psychiatry 36, 179-187.

Hankin, B. L., Abramson, L. Y., Moffit, T. E., Silva, P. A., McGee, R. \& Angell, K. E. (1998). Development of depression from preadolescence to young adulthood: emerging gender differences in a 10-year longitudinal study. Journal of Abnormal Psychology 107, 128-140.

Harrington, R., Fudge, H., Rutter, M., Pickles, A. \& Hill, J. (1990). Adult outcomes of childhood and adolescent depression. I. Psychiatric status. Archives of General Psychiatry 47, 465-473.

Harrington, R., Fudge, H., Rutter, M., Pickles, A. \& Hill, J. (1991). Adult outcomes of childhood and adolescent depression. II. Links with antisocial disorders. Journal of the American Academy of Child and Adolescent Psychiatry 30, 434-439.

Jensen, P. S., Koretz, D., Locke, B. Z., Schneider, S., RadkeYarrow, M., Richters, J. E. \& Rumsey, J. M. (1993). Child and adolescent psychopathology research: problems and prospects for the 1990s. Journal of Abnormal Child Psychology 21, 551-580.

Kaplan, E. L. \& Meier, P. (1958). Nonparametric estimation from incomplete observations. Journal of the American Statistical Association 53, 457-481.

Kashani, J. H., Orvaschel, H., Rosenberg, T. K. \& Reid, J. C. (1989). Psychopathology in a community sample of children and adolescents: a developmental perspective. Journal of the American Academy of Child and Adolescent Psychiatry 28, 701-706.

Kessler, R. C., McGonagle, K. A., Swartz, M., Blazer, D. G. \& Nelson, C. B. (1993). Sex and depression in the National Comorbidity Survey I: Lifetime prevalence, chronicity and recurrence. Journal of Affective Disorders 29, 85-96.

Kessler, R. C., McGonagle, K. A., Nelson, C. B., Hughes, M., Swartz, M. \& Blazer, D. G. (1994). Sex and depression in the national comorbidity study: II. Cohort effects. Journal of Affective Disorders 30, 15-26.

Klein, D. N., Norden, K. A., Ferro, T., Leader, J. B., Kasch, K. L., Klein, L. M., Schwartz, J. E. \& Aronson, T. A. (1998). Thirtymonth naturalistic follow-up study of early-onset dysthymic disorder: course, diagnostic stability, and prediction of outcome. Journal of Abnormal Psychology 107, 338-348.

Kovacs, M. (1996). Presentation and course of major depressive disorder during childhood and later years of the life span. Journal of the American Academy of Child and Adolescent Psychiatry 35, 705-715.

Kovacs, M. \& Gatsonis, C. (1994). Secular trends in age at onset of major depressive disorder in a clinical sample of children. Journal of Psychiatry Research 28, 319-329.

Kovacs, M., Gatsonis, C., Paulauskas, S. L. \& Richards, C. (1989). Depressive disorders in childhood. IV. A longitudinal study of comorbidity with and risk for anxiety disorders. Archives of General Psychiatry 46, 776-782.

Kovacs, M., Akiskal, H. S., Gatsonis, C. \& Parrone, P. L. (1994). Childhood-onset dysthymic disorder. Clinical features and prospective naturalistic outcome. Archives of General Psychiatry 51, 365-374.

Lachner, G., Wittchen, H.-U. \& Perkonigg, A. (1998). Structure, content and reliability of the Composite International Diagnostic Interview. European Addiction Research 4, 28-41. 
Lewinsohn, P. M., Hops, H., Roberts, R. E., Seeley, J. R., Rohde, P., Andrews, J. A. \& Hautzinger, M. (1992). Affektive Störungen be Jugendlichen: Prävalenz, Komorbidität und psychosoziale Korrrelate (Adolescent psychopathology: prevalence, comorbidity, and psychosocial correlates). Verhaltenstherapie 2, 132-139.

Lewinsohn, P. M., Hops, H., Roberts, R. E., Seeley, J. R. \& Andrews, J. A. (1993). Adolescent psychopathology: I. Prevalence and incidence of depression and other DSM-III-R disorders in high school students. Journal of Abnormal Psychology 102, 133-144.

Lewinsohn, P. M., Clarke, G. N., Seeley, J. R. \& Rohde, P. (1994) Major depression in community adolescents: age at onset, episode duration, and time to recurrence. Journal of the American Academy of Child and Adolescent Psychiatry 34, 454-463.

Links, P. S., Boyle, M. H. \& Offord, D. R. (1989). The prevalence of emotional disorder in children. Journal of Nervous and Mental Disease 177, 85-91.

National Institute of Mental Health (1992). Diagnostic Interview Schedule for Children (DISC), Version 2.3. New York State Psychiatric Institute, Division of Child and Adolescent Psychiatry: New York.

Offord, D. R., Boyle, M. H., Campbell, D., Goering, P., Lin, E., Wong, M. \& Racine, Y.A. (1996). One-year prevalence of psychiatric disorder in Ontarians 15 to 64 years of age. Canadian Journal of Psychiatry 41, 559-563.

Orvaschel, H., Puig-Antich, J., Chambers, W. J., Tabrizi, M. A. \& Johnson, R. (1982). Retrospective assessment of prepubertal major depression with the Kiddie-SADS-E. Journal of the American Academy of Child Psychiatry 21, 392-397.

Petersen, A. C., Compas, B. E., Brooks-Gunn, J., Stemmler, M., Ey, S. \& Grant, K. E. (1993). Depression in adolescence. American Psychologist 48, 155-168.

Pine, D. S., Cohen, P., Gurley, D., Brook, J. \& Ma, Y. (1998). The risk for early-adulthood anxiety and depressive disorders in adolescents with anxiety and depressive disorders. Archives of General Psychiatry 55, 56-64.

Rao, U., Ryan, N. D., Birmaher, B., Dahl, R. E., Williamson, D. E., Kaufman, J., Rao, R. \& Nelson, B. (1995). Unipolar depression in adolescents: clinical outcome in adulthood. Journal of the American Academy of Child and Adolescent Psychiatry 34, 566-578.

Reed, V., Gander, F., Pfister, H., Steiger, A., Sonntag, H., Trenkwalder, C., Hundt, W. \& Wittchen, H.-U. (1998). Testing validity issues of the CIDI in a clinical sample. International Journal of Methods in Psychiatric Research 7, 142-155.

Roberts, R. E., Attkisson, C. C. \& Rosenblatt, A. (1998). Prevalence of psychopathology among children and adolescents. American Journal of Psychiatry 155, 715-725.

Robins, J. N., Helzer, J. E., Crougham, R., Williams, J. B. \& Spitzer, R. L. (1981). National Institute of Mental Diagnostic Interview Schedule: Version III. National Institute of Mental Health: Rockville, MD.
Simonoff, E., Pickles, A., Meyer, J. M., Silberg, J. L., Maes, H. H., Loeber, R., Rutter, M., Hewitt, J. K. \& Eaves, L. J. (1997). The Virginia twin study of adolescent behavioral development: influences of age, sex, and impairment on rates of disorder. Archives of General Psychiatry 54, 801-808.

Steinhausen, H. C., Metzker, C. W., Meier, M. \& Kannenberg, R. (1998). Prevalence of child and adolescent psychiatric disorders: the Zürich Epidemiological Study. Acta Psychiatrica Scandinavica 98, 262-271.

StataCorp. (1997). Stata Statistical Software: Release 5.0. Stata Corporation: College Station, TX.

Üstün, T. B. \& Sartorius, N. (1995). The background and rationale of the WHO collaborative study on 'Psychological Problems in General Health Care'. In Mental Illness in General Health Care (ed. T. B. Üstün and N. Sartorius). Wiley: New York.

Verhulst, F. C., Ende, J. van der, Ferdinand, R. F. \& Kasius, M. C. (1997). The prevalence of DSM-III-R diagnoses in a national sample of Dutch adolescents. Archives of General Psychiatry 54, 329-336.

Whittaker, A., Johnson, J., Schaffer, D., Rapoport, J. L., Kalikow, K., Walsh, B. T., Davies, M., Braiman, S. \& Dolinsky, A. (1990). Uncommon troubles in young people: prevalence estimates of selected psychiatric disorders in a nonreferred adolescent populations. Archives of General Psychiatry 47, 487-496.

Winer, B. J. (1971). Statistical Principles in Experimental Design (2nd edn). McGraw-Hill: New York.

Wittchen, H.-U. \& Pfister, H. (1997). Diagnostisches Expertsystem für Psychische Störungen DIA-X (Diagnostic expert system for mental disorders DIA-X). Swets \& Zeitlinger BV: Frankfurt.

Wittchen, H.-U., Nelson, C. B. \& Lachner, G. (1998a). Prevalence of mental disorders and psychosocial impairments in adolescents and young adults. Psychological Medicine 28, 109-126.

Wittchen, H.-U., Perkonigg, A., Lachner, G. \& Nelson, C. B. $(1998 b)$. Early Developmental Stages of Psychopathology (EDSP): objectives and design. European Addiction Research 4, 18-27.

Wittchen, H.-U., Lachner, G., Wunderlich, U. \& Pfister, H. (1998c). Test-retest reliability of the DSM-IV version of the M-CIDI. Social Psychiatry and Psychiatric Epidemiology 33, 568-578.

Wittchen, H.-U., Lieb, R., Schuster, P. \& Oldehinkel, A. J. (1998d). When is onset? Investigations in early developmental stages of anxiety and depressive disorders. American Psychiatric Press (in the press).

Wittchen, H.-U., Schuster, P., Pfister, H., Müller, N., Storz, S. \& Isensee, B. (1999). Nicht behandelte Depressionen in der Allgemeinbevölkerung: das Ausmaß des Problems (Untreated depressions in the community: the size of the problem). Journal of Nervenheilkunde (in the press).

World Health Organization (1990). Composite International Diagnostic Interview (CIDI). World Health Organization: Geneva. 